\title{
Project Performance Analysis Using the Earned Value Management (EVM) Method (Case Study: PT XYZ)
}

\author{
Akhmad Ittang Anwarsyah ${ }^{1}$ and Ervina Ahyudanari ${ }^{2}$
}

\begin{abstract}
The development of the construction in Indonesia is growing rapidly over time, along with rapid economic growth. In its implementation, many projects have problems with work delays so that the project completion is not in accordance with the scheduled time and results in increased costs due to additional completion time. This delay puts the contractor to do a re-planning or commonly referred to as a re-baseline. The inaccuracy of re-planning can have an impact on not achieving revenue targets and having a commercial impact on the construction company. a project performance analysis is needed to anticipate these problems as early as possible. The method used to analyze project performance with a review of the implementation time and budget to manage the dynamics that occur is to use the Earned Value Management method. EVM is a method that is used to determine the progress of a project greater or smaller than the budgeted budget and faster or slower than a predetermined schedule. This study shows that EVM parameters, namely SPI and CPI on 3 PT Projects. XYZ shows both in the field of work (SPI) or budget planning (CPI), PT. $X Y Z$ still shows a performance that is not good enough. Whereas EVM Analysis on $3 \mathrm{XYZ}$ Projects shows that the cost requirements needed for project completion are above the budget. The Sugar Factory EPCC Project A based on EVM will require $107 \%$ of the $B A C$ value for completion of work, the EVM-based Cooking Plant Construction Project will require $110 \%$ BAC for completion of work and the Sugar Factory EPCC Project $B$ based on $E V M$ will require $106 \%$ BAC to complete the work. Referring to the EAC calculation and risk mitigation for the costs needed, the Project for the Construction of Edible Oil Plants has the greatest potential to be able to reduce business yields. Through EVM, it was also found that the time for implementing the three projects increased from the duration of the initial planning. The EPCC Project for Sugar A Factory increased for 6 Months, the Cooking Oil Plant Construction Project increased for 5 months and the EPCC Sugar Factory B Project increased for 2 months.
\end{abstract}

Keywords-Earned Value Management, Project Performance Analysis, Construction, Re-Baseline.

\section{INTRODUCTION}

The development of construction in Indonesia is growing

\footnotetext{
${ }^{1}$ Akhmad Ittang Anwarsyah is with Departement of Management Technology, Institut Teknologi Sepuluh Nopember, Surabaya, 60264, Indonesia. E-mail: akhmadittang@gmail.com

${ }^{2}$ Ervina Ahyudanari is with Departement of Civil Engineering, Institut Teknologi Sepuluh Nopember, Surabaya, 60111, Indonesia. E-mail: ervina@ce.its.ac.id
}

rapidly over time, along with rapid economic growth. Construction activities are mostly carried out in various regions in Indonesia along with government concern to support economic growth. In project management, an integrated system is needed which is called project management to anticipate or manage project to achieving project objectives, as time, cost and quality. But in its implementation, many projects still have some problems including the occurrence of errors in the calculation of project time and errors in estimating project costs due to the calculation of project time and costs based on estimates. This delays projects causes delay of completion. So the project cannot be completed in accordance with the scheduled time and causes increased project costs due to the additional time of the project.

PT.XYZ was established since 59 years ago is a stateowned enterprise (BUMN) construction services company that is engaged in EPC (Engineering, Procurement, and Construction) and integrated investment. Based on the type of project, for several years XYZ has worked on various types of projects, including EPC (Engineering Procurement Construction) namely Industrial Plant, Building and Stuctur namely DBG and Public infrastructure. As one of the biggest construction companies in Indonesia, XYZ also have same problems as other construction company in general, which is a mismatch of budget planning with the realization of the budget spent which causing delays in project completion. This delay makes the contractor to do a re-planning or commonly called as a re-baseline. Replanning by the contractor commonly using the Critical Path Method (CPM) method. Critical Path Method can provide information to the project manager to evaluate the earliest time starting and the last time an activity starts, calculate the duration of activity duration (float / slack), make sure the critical activities and evaluate the impact of changing duration with the relationship between activities and costs on the whole project. In the actual condition, this re-planning are only design based on the acceleration of the duration of completion without involving financial cash flows from crash costs that occur by the crash program. The direct costs of the project will increase with the addition of working hours, this is referred to as crash costs.

The method used to analyze the performance of project that has been implemented by XYZ so far are Key Performance Indicator (KPI) method which the 
implementation of these analysis is not enough to describe the dynamic conditions that occur in the implementation. This is due to the parameters specified in the KPI design based on the overall of the project at PT. Wijaya Karya.

Another method that can be used to analyze project performance based on implementation and budget that can accommodate the dynamics are the Earned Value Management method. EVM is a method used to determine the progress of a project larger or smaller than the budget budgeted or faster or slower than a predetermined schedule. EVM can also provide information about the position of progress of the project in the term certain time and estimate the progress of the project in the next period both in terms of costs and project completion time. The interaction between the three elements of project management (scope, cost and time) carried out with EVM which provide project managers with information about the performance and progress of work during the project life cycle. Such information can be an important consideration for project managers to identify what needs to be done to bring the project back to the direction that is in line with the target time and cost

EVM is defined by analysis the cost performance with the calculation parameters largely determined by the stability of the cost index / CPI (Cost Performance Indicator). There are three main reasons why the stability of the CPI is very important to note. First, CPI is a parameter used in EVM calculations. Second, the stability of the CPI is an indication that cost control has been running smoothly because variance has been detected early. Third, the stability of the CPI can be a comparison with the Index of settlement performance and can be a foundation for good implementation. The cumulative result of CPI stability is when the project is in progress $20 \%$. This stability shows that the CPI end result of EVM analysis does not vary more than 20\% CPI when progress is 20\%. The results of EVM analysis both CPI and SPI can be used as the basis for the preparation of project re-baselines in the remainder of the completion to remain in line with the initial planning both time and cost.

\section{REVIEW OF LITERATURE AND BASIC THEORY}

\section{A. Earned Value Management}

Earned Value Management (EVM) is a control methodology and project performance measurement based on the interaction between three elements of project management (scope, cost and time). [1]. Earned Value method is a method that calculates the amount of costs according to the budget in accordance with the work that has been completed. This method are measured by the amount of completed activities, so this method measures the amount of work units that have been completed based by budget that been provide for those. The relationship between what has actually been achieved physically to the amount of the budget that has been spent. By using this method, ongoing project performance can be seen, so that the adjustment can be done if there is a deviation from the initial project plan.

Implentation of EVM is needed the scope of work, the implementation budget and work schedule so that the integration of the three things can be done. Planning phase, the implementation budget must be in accordance with the overall budget plan for each activity implementation. By doing accumulated calculations from all budget planning that is adjusted to the work schedule, the budget will be needed for the entire project, Planned Value (PV). Planned Value is the value planned to be achieved referring to the initial planning of the project. The accumulation of PV at the end of the project is called Budget At Completion (BAC). Implementation phase of project work there are two values obtained so that it can be a comparison between planning and realization. Earned Value (EV) is a value obtained on the entire project at that time. The EV value can be obtained by the final project value (BAC) multiplied by the percentage of work up to that time.

The second value is the realization of the budget, Actual Cost (AC) is the value of the realization of the budget that has been issued until that time. In Figure 1, it is explained that the AC value is the accumulation of budget realization until then.

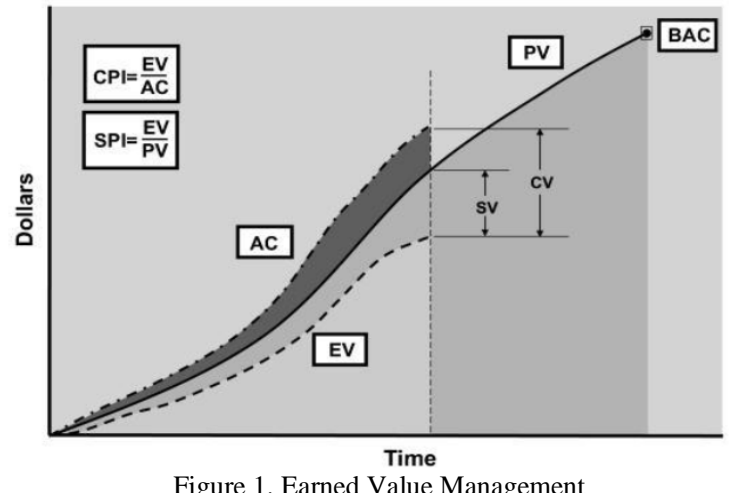

\section{B. Earned Value Management Parameter}

\section{1) Variance}

Variation parameters show how far the current status of project implementation is compared to initial planning. Cost Variance (CV) or budget variation is an indicator of the development of budget planning. $\mathrm{CV}$ is done to find out the budget realization exceeds or less than the planned budget that was planned at the beginning of the project. Schedule Variance (SV) or schedule variation is an indicator that represents the accuracy of implementation with a work schedule. SV is carried out to find out the realization of work implementation beyond or late from the schedule planned at the beginning of the project.
Cost Variance
$: \mathrm{CV}=\mathrm{EV}-\mathrm{AC}$
Schedule Variance

$$
\text { : SV=EV-PV }
$$


The $1^{\text {st }}$ International Conference on Business and Management of Technology (IConBMT)

August 3rd 2019, Institut Teknologi Sepuluh Nopember, Surabaya, Indonesia

\section{2) Performance Index}

Performance parameters show how effective the current project is compared to the initial planning. The Cost Performance Index (CPI) shows the level of budget efficiency in project implementation. If the CPI value is less than 1 , the project is going through more budget planning. The Schedule Performance Index (SPI) shows the suitability of the work and schedule. If the SPI value is less than 1 , the project work is delayed from the planning schedule.

Cost Performance Index $\quad:$ CPI $=$ EV $/$ AC

Schedule Performance Index $\quad:$ SPI $=\mathrm{EV} / \mathrm{PV}$

3) Estimated Time and Costs for Project Completion

According to Jacod D.S (2003), estimates are calculated based on trends in project performance at the time of review and assume that these trends do not change project performance until the end of the project or the project performance is constant. This estimate is useful for providing a forward-looking picture to the contractor, so that they can take the necessary corrective steps.

a. Estimated at Completion (EAC cost)

Calculation of Estimation at Completion (Cost) consists of Realization of Outgoing Costs (AC) and Estimated costs needed to complete the project (Estimation at Completion, EAC). There are various types of EAC calculations, while in this study the calculation formula for EAC (Cost) used is as follows:

$$
\mathrm{EACcost}=\mathrm{AC}+((\mathrm{BAC}-\mathrm{EV}) / \mathrm{CPI})
$$

\section{b. Estimated Duration (Date)}

Estimation Duration (Date) calculation consists of Time in the initial planning (Planned Duration) and performance index of the implementation time (Schedule Performance Index). Based on these parameters, the calculation of the total time needed for project completion is obtained, while in this study the Estimated Duration calculation formula used is as follows:

$$
\mathrm{ED}=(\mathrm{PD} / \mathrm{SPI})
$$

\section{4) Rebaseline}

According to [2], the initial planning of the project or commonly referred to as the project baseline is planning that is arranged at the initialization stage. In some activities in the planning it is difficult to estimate and depends on other activities, therefore the project baseline is generally prepared with high uncertainty. During project implementation it is known that the initial baseline is not in accordance with the conditions of realization of the implementation. This is due to changes in the scope, schedule, cost or combination of these factors. Re-baseline or rearrangement of planning is an effort made so that the implementation of the project can be managed again as shown in Figure 2 and 3.

In Figure 2, it can be seen that the AC percentage rate is higher than the planned value, it shows that the occurrence of additional costs incurred refers to the change in budget planning, it needs to be adjusted. In Figure 2 EV obtained at time $\mathrm{S}$ is lower than the value planned at the baseline, this shows that the progress of the work completion is less than the planning refers to it. Adjustments to the implementation time need to be done to determine the project expiration time.

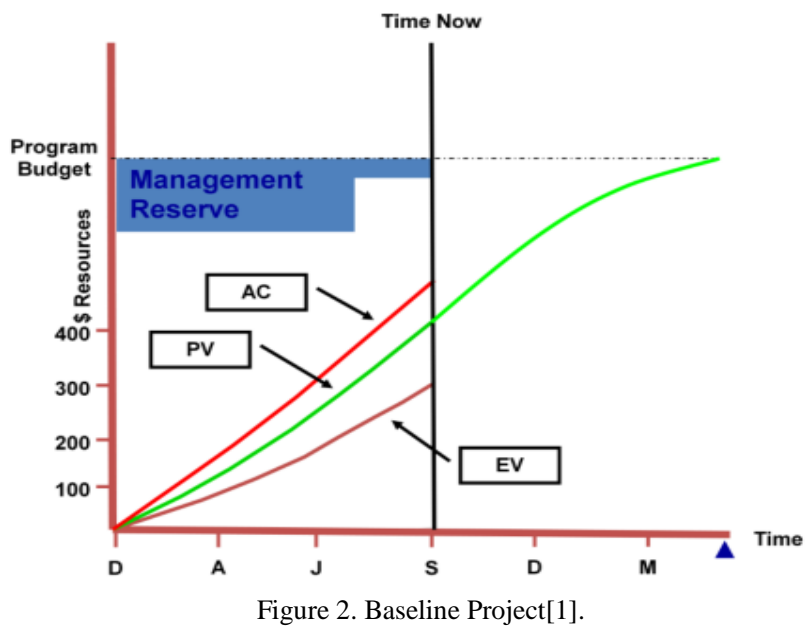

Figure 3 shows that project planning adjustments have been made with reference to the AC percentage value. The implementation time, duration of implementation and budget planning of all activities are adjusted to the conditions of realization of the project. This generally leads to higher budgets and longer completion times.

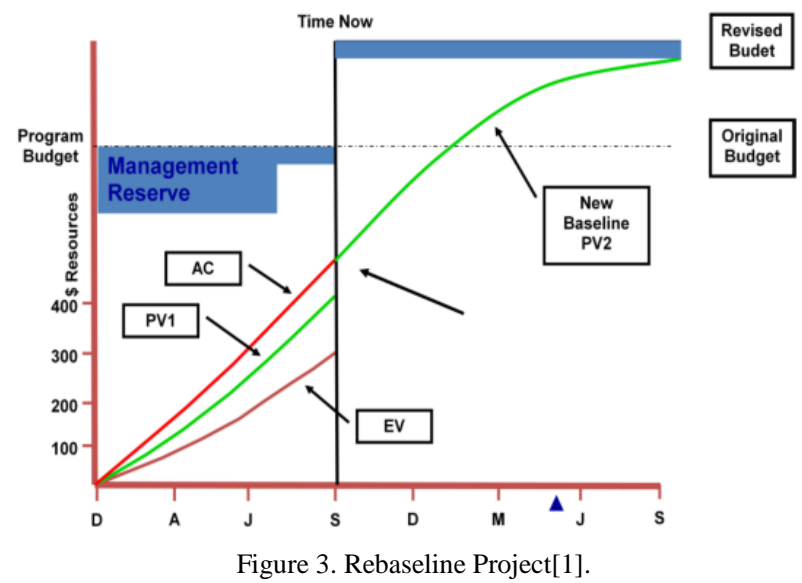

The design of rebaseline must be made not too different from the initial planning using a forecasting method that takes into account the realization of the budget and the realization of the duration of the work. Rebaseline aims to return a variety of costs and the schedule becomes zero and the performance of the index back into one thing produces you a better estimate in its implementation. The obstacle faced in the implementation of rebaseline is that the project management team needs to review the implementation so that there is no re-variation[2]. 


\section{RESEARCH METHODS}

This research is a research on performance analysis using the Earned Value Management method in the world of construction industry. According to Arikunto (2006), exploratory research is research that aims to explore extensively about the causes or things that affect the occurrence of something. Explorative research is used when we do not know exactly and specifically about the object of our research. PT. Wijaya Karya (Persero) Tbk cooperatively has not implemented EVM performance analysis on the implementation of projects. From the literature study that has been done, it was found that empirical evidence of the performance of EVM with contrusion projects often does not work well. According to Henderson, Zwikael, (2008) of the 20 construction projects in the United Kingdom (UK), only 2 projects showed CPI stability in implementation progress of $20 \%$ while 12 projects did not show stability at all. According to Vargas (2009) the performance analysis method using EVM is an excellent tool in controlling and evaluating implementation, but only for projects that have data that can be processed properly.

\section{A. Data Collection}

This study uses secondary data, namely data obtained by researchers directly in the project control and planning department of PT. Wijaya Karya and focuses on major projects that have been completed in the period 2014 to 2018 with reference to projects that have submitted EOT (Extention of Time). In this study the data analyzed came from 3 completed Construction Projects as follows:

1. EPCC Project Sugar Factory Assembagoes.

2. Project for the Construction of the Cooking Oil Plant.

3. EPCC Project Sugar Factory Rendeng.

From the three projects above, the following data are obtained:

1. Schedule work on project implementation at an early stage.

2. The project implementation budget plan at the initial stage.

3. Information about the actual duration of activities in the project.

4. Information about actualization of budget expenditures.

5. Changes to work schedules and changes to budget planning.

6. Budget and final project duration.

B. Research Steps

The research steps are a form of preparation effort before carrying out systematic research which includes planning, procedures and technical implementation in the field. This is so that the research that will be carried out can run according to what was planned. The steps of this research can be seen in Figure 4.

The stability of CPI and SPI is done by comparing CPI and SPI data from the 3 projects. Comparison of the stability of the CPI and SPI of the five projects is carried out in progress of $20 \%$. According to the results of Lipke, Zwikel, Henderson, Anbari, 2009 the cumulative of the stability of CPI and SPI at the time of project implementation is in progress of $20 \%$. This stability shows that the CPI end result of the EVM analysis does not vary more than $10 \%$ CPI when progress is $20 \%$.

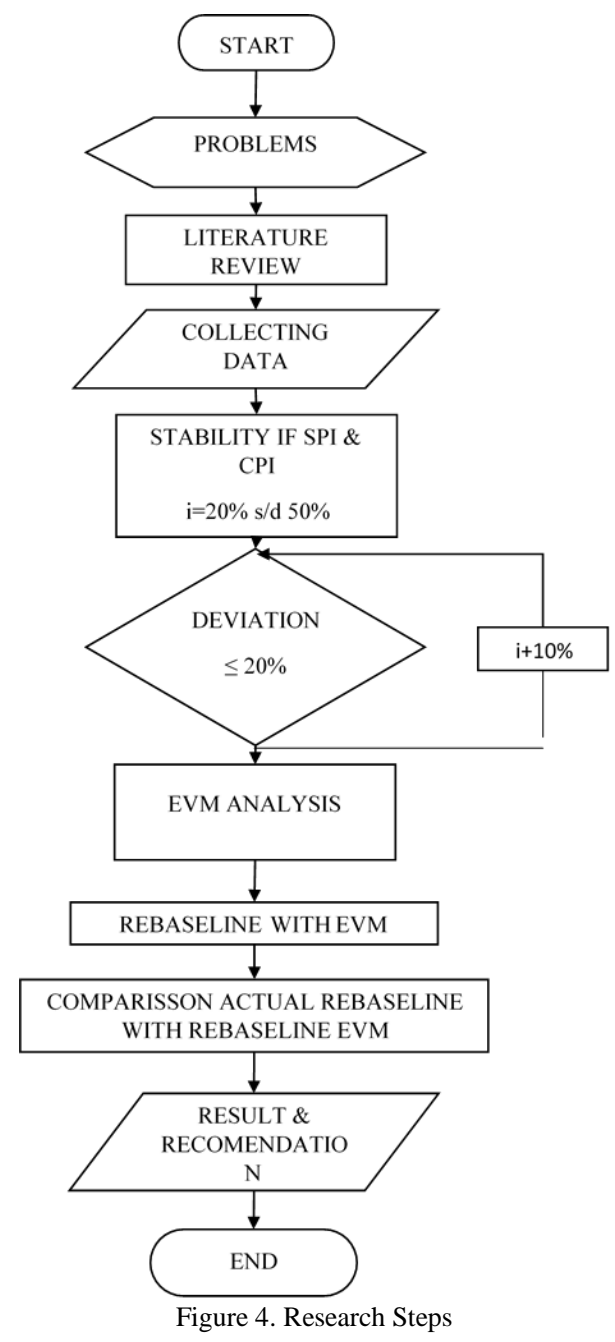

If the stability of the 3rd CPI and SPI of the Project has a variation of more than $20 \%$, the comparison of CPI and SPI will be done by calculating CPI and SPI by adding progress of $10 \%$ to $50 \%$ stability of CPI and SPI with variations of less than 20\%. PT. WIjaya Karya (Persero) Tbk. in the WIKA Procedure Context Diagram, it is conveyed that the $\mathrm{S}$-Curve evaluation is carried out in the progress of $0 \%$ to $50 \%$ implementation.

\section{RESUlTS AND ANALYSIS}

\section{A. Data Collection}

EPCC Sugar Factory A Project planned to completed with a 19-month implementation period with mechanical completion achieved in the 19th month. In figure 5 
planning begins with implementation of the engineering phase followed by the procurement phase and continued with the construction phase until mechanical completion achieved. Mechanical completion achieved at a $98 \%$ implementation progress, leaving $2 \%$ for the commissioning phase of the plant. The critical path (Critical Path) in this first planning lies in the activities of boiler work with vendors from outside Indonesia.

The critical path (Critical Path) in this first planning lies in boiler work activities with vendors from outside Indonesia. On the real condition as seen on figure 5 EPCC Sugar Factory A Project does not work by the planned first planning. Until the implementation period in the 13th month the progress of the EPCC Sugar Factory A Project work is still better than planning with deviation of $0.10 \%$. This positive deviation occurs at the cumulative real progress which is not directly proportional to the planned progress of the work every month.

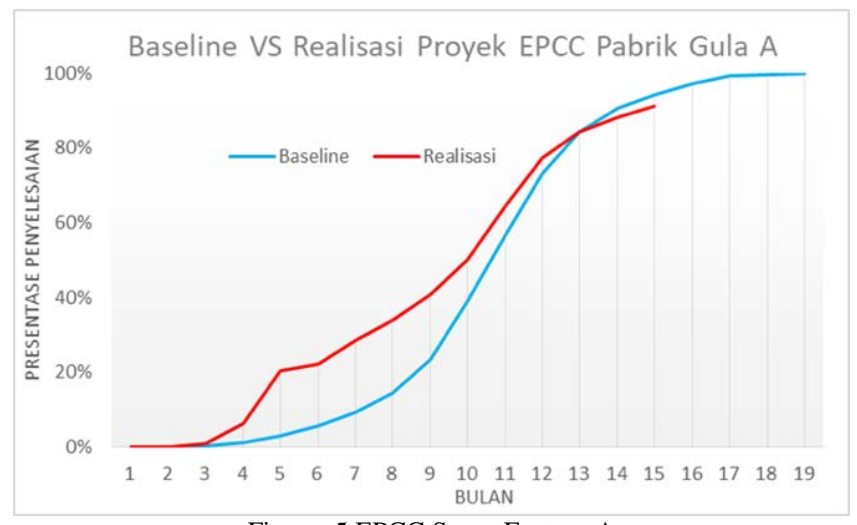

Figure. 5 EPCC Sugar Factory A

The SPI and CPI values in Table 1 show that the implementation of the EPCC S.F Assembagoes have an SPI value of less than 1 where it shows that implementation runs slower than planning. During the 9th to 15th month of EPCC Sugar Factory A Project continuously has a value below 1 . Table 1 shows also that the EPCC PG project have a CPI value of less than 1 where it shows that the costs incurred are greater than the cost planning. During the 9th to 15th month of the CPI EPCC Sugar Factory A Project continuously has a value below 1 .

Project for the Construction of Edible Oil Plant is planned to be completed with a 21-month implementation time with mechanical completion can be achieved in the 20th month. In Figure 6 planning begins with the implementation of the engineering phase followed by the procurement phase and continues with the construction phase until a mechanical completion is achieved. Mechanical completion is achieved in $96 \%$ implementation progress by leaving $4 \%$ for the plant commissioning / trial phase. The critical path (Critical Path) in this initial planning lies in the steel structure work activities, refineries and equipment-equipment from Lipico as the technology provider.
Figure 6 shown us that Project for the Construction of Edible Oil Plant is not in accordance with the planned initial planning. Until the implementation period in the 13th month the progress of the project work was still better than the planning with a positive deviation of $0.32 \%$. This positive deviation occurs at the cumulative of actual progress which is not directly proportional to the planned progress of the work every month.

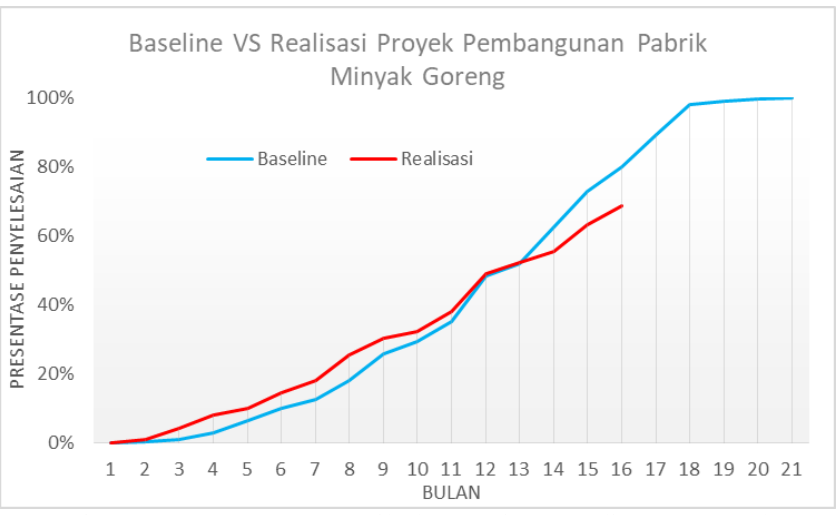

Figure 5. 600,000 MTPY Oil Plant Project Baseline VS Actual

The SPI and CPI values in table 2 show that the implementation of the 600,000 MTPY Edible Oil Mill Project has an SPI value of less than 1, which indicates that the implementation runs slower than planning. In the implementation period of the 12th to 16th month of the SPI the Project for the Construction of Edible Oil Plants continuously has a value below 1 .

Table 2 also shows that the implementation of Project for the Construction of Edible Oil Plants has a CPI value of less than 1, which indicates that the costs incurred are greater than the cost planning. During the 9th to 16th month of the Project for the Construction of Edible Oil Plants continuously has a value below 1 .

EPCC Sugar Factory B Project is planned to be completed with a 25-month implementation time with mechanical completion achieved in the 22nd month. In Figure 7 the planning begins with the implementation of the engineering phase followed by the procurement phase and continues with the construction phase until mechanical completion is achieved. Mechanical completion is achieved in $97 \%$ implementation progress by leaving 3\% for the plant commissioning / trial phase. The critical path (Critical Path) in this initial planning lies in boiler work activities with vendors from outside Indonesia.

In figure 7 Shown us that EPCC Sugar Factory B Project does not work in accordance with the planned initial planning. Until the implementation period in the 12th month the progress of the EPCC Sugar Factory B Project work is still better than planning with a positive deviation of $4.5 \%$. This positive deviation occurs at the cumulative realiation which is not directly proportional to the planned progress of the work every month. 


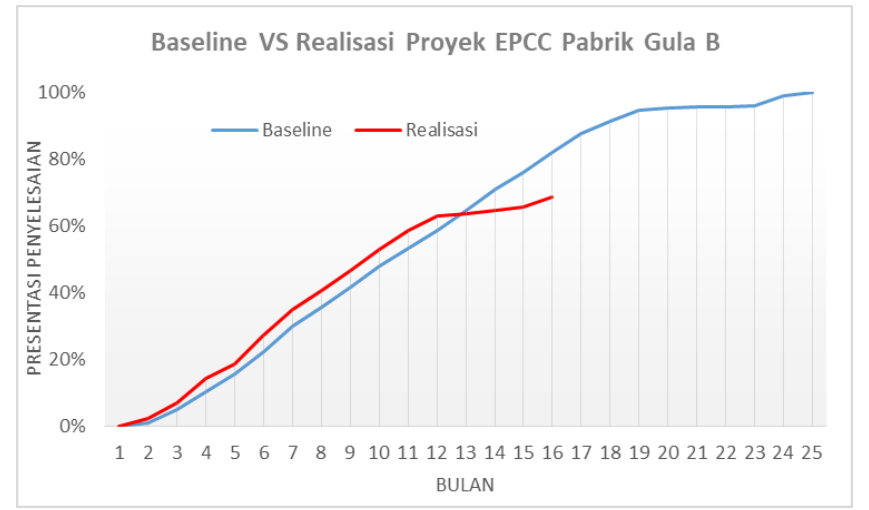

Figure 5. S.F Rendeng Baseline VS Actual

The values of SPI and CPI in table 3 show that the EPCC Sugar Factory B Project has an SPI value of less than 1 where it shows that implementation runs slower than planning. In the implementation period of the 12th to 16th month the SPI EPCC Sugar Factory B Project continuously has a value below 1 .

Table 3 also shows that the implementation of the EPCC Sugar Factory B Project has a CPI value of less than 1 where it shows that the costs incurred are greater than the cost planning. In the implementation period of the 12th to the 15th month of the CPI EPCC Sugar Factory B Project continuously has a value below 1 .

\section{B. Stability of SPI and CPI}

Measurement of CPI and SPI with additional progress of $10 \%$ to $50 \%$ stability with variations of less than $20 \%$. $\mathrm{PT}>\mathrm{XYZ}$. in the XYZ Procedure Context Diagram, it is conveyed that the S-Curve evaluation is carried out in the progress of $0 \%$ to $50 \%$ implementation. The stability of the CPI value of the three projects shows a deviation in progress of $20 \%$ by $76 \%$. Whereas in the $30 \%$ program a deviation of $22 \%$ occurred and Progess $40 \%$ and $50 \%$ respectively showed deviations as much as $20 \%$ and $47 \%$. The stability of the SPI value of the three projects shows a deviation in progress of $20 \%$ by $84 \%$. Whereas in the $30 \%$ program there is a deviation of $44 \%$ and Progess of $40 \%$ and $50 \%$ respectively shows deviations as much as $19 \%$ and $41 \%$.

Based on the measurement of CPI and SPI stability above, it was found that the stability of CPI and SPI between the three projects occurred in $40 \%$ work progress with a deviation value of less than $20 \%$. EVM calculations will be made on $40 \%$ work progress.

\section{Earned Value Management \\ 1) Estimated at Completion}

\section{a. EPCC Sugar Factory A Project}

The cost needed for project completion compared to the BAC value is $107 \%$, it shows that financially for the completion of the work, the EPCC PG. Assembagoes project has the potential to exceed the budget of $7 \%$. The $7 \%$ charge is accommodated in the efficiency budget so as not to disrupt the business risk and corporate profit.

b. Project for the Construction of Edible Oil Plants

The cost needed for the completion of the project compared to the BAC value is $110 \%$, it shows that financially for the completion of the work Project for the Construction of Edible Oil Plant has the potential to exceed the budget of $10 \%$. The $10 \%$ charge is accommodated in the efficiency budget and leaves 3\% in the risk budget so that it does not disturb the coorporate profit.

c. EPCC Sugar Factory B Project

The cost needed to complete the project compared to the BAC value is $106 \%$, this shows that financially for the completion of the work, the EPCC Sugar B project has the potential to exceed the budget of $6 \%$. The $6 \%$ loading is accommodated in the efficiency budget and leaves $1 \%$ in the efficiency budget so it does not interfere with the risk budget and business margins.

TABLE 1.

SPI \& CPI EPCC SUGAR FACTORY A PROJECT

\begin{tabular}{|c|c|c|c|c|c|c|c|c|c|c|c|c|c|c|c|c|c|c|c|}
\hline MONTH & 1 & 2 & 3 & 4 & 5 & 6 & 7 & 8 & 9 & 10 & 11 & 12 & 13 & 14 & 15 & 16 & 17 & 18 & 19 \\
\hline SPI & 1 & 1 & 1,89 & 7,8 & 8,1 & 0,6 & 1,7 & 1,1 & 0,77 & 0,6 & 0,8 & 0,8 & 0,63 & 0,6 & 0,86 & & & & \\
\hline CPI & 1 & 1 & 2,9 & 10 & 8,6 & 1,09 & 2,3 & 1 & 0,7 & 0,6 & 0,9 & 0,8 & 0,5 & 0,5 & 0,59 & & & & \\
\hline
\end{tabular}

TABLE 2.

SPI \& CPI PROJECT FOR THE CONSTRUCTION OF EDIBLE OIL PLANTS

\begin{tabular}{cccccccccccccccccccccc}
\hline \hline MONTH & 1 & 2 & 3 & 4 & 5 & 6 & 7 & 8 & 9 & 10 & 11 & 12 & 13 & 14 & 15 & 16 & 17 & 18 & 19 & 20 & 21 \\
\hline SPI & 1 & 2,5 & 4,6 & 2,3 & 0,6 & 1,2 & 1,5 & 1,3 & 0,6 & 0,6 & 1,0 & 0,8 & 0,9 & 0,3 & 0,7 & 0,8 & & & & \\
CPI & 1 & 3,3 & 7,1 & 4,2 & 1,3 & 2,0 & 2,2 & 1,5 & 1,1 & 0,8 & 1,2 & 0,7 & 0,7 & 0,2 & 0,7 & 0,6 & & & & \\
\hline \hline
\end{tabular}

TABLE 3.

SPI \&CPI EPCC SUGAR FACTORY B PROJECT

\begin{tabular}{|c|c|c|c|c|c|c|c|c|c|c|c|c|c|c|c|c|c|c|c|c|}
\hline MONTH & 1 & 2 & 3 & 4 & 5 & 6 & 7 & 8 & 9 & 10 & 11 & 12 & 13 & 14 & 15 & 16 & 17 & 18 & 19 & $20-25$ \\
\hline SPI & 1 & 2,1 & 1,3 & 1,3 & 0,8 & 1,3 & 1,0 & 1,0 & 1,0 & 1,0 & 1,0 & 0,9 & 0,1 & 0,2 & 0,2 & 0,5 & & & & \\
\hline CPI & 1 & 3,8 & 1,9 & 1,4 & 1,0 & 1,7 & 1,2 & 0,8 & 1,1 & 1,2 & 1,2 & 0,9 & 0,1 & 0,2 & 0,2 & 0,6 & & & & \\
\hline
\end{tabular}




\section{2) Estimated at Completion}

a. EPCC Sugar Factory A Project

Estimation Duration (Date) calculation consists of Time in the initial planning (Planned Duration) and performance index of implementation time (Schedule Performance Index), the ED calculation formula used is as follows:

$$
\mathrm{ED}=(\mathrm{PD} / \mathrm{SPI})
$$

In the $40 \%$ progress of the EPCC Sugar Factory A Project, get the following data:

$\mathrm{PD}=19$ Months

$\mathrm{SPI}=0.77$

Then from this data ED can be obtained as follows,

$\mathrm{ED}=(19 / 0.77)$

$=24.67 \approx 25$ Months

The time needed to complete all work on the EPCC Sugar Factory A Project is 25 Months, which shows that the completion time increased for 6 months from the initial planning.

b. Project for the Construction of Edible Oil Plants

Estimation Duration (Date) calculation consists of Time in the initial planning (Planned Duration) and performance index of implementation time (Schedule Performance Index), the ED calculation formula used is as follows:

$$
\mathrm{ED}=(\mathrm{PD} / \mathrm{SPI})
$$

In the progress of $40 \%$ of Project for the Construction of Edible Oil Plants, data was obtained as follows:

$\mathrm{PD}=21$ Months

$\mathrm{SPI}=0.83$

Then from this data ED can be obtained as follows,

$\mathrm{ED}=(21 / 0.83)$

$$
=25.30 \approx 26 \text { Months }
$$

The time needed to complete all work on Project for the Construction of Edible Oil Plants is 26 Months. This shows that the completion time increased for 5 months from the initial planning.

\section{c. EPCC Sugar Factory B Project}

Estimation Duration (Date) calculation consists of Time in the initial planning (Planned Duration) and performance index of implementation time (Schedule Performance Index), the ED calculation formula used is as follows:

$$
\mathrm{ED}=(\mathrm{PD} / \mathrm{SPI})
$$

In the $40 \%$ progress of the EPCC Sugar Factory B Project, got the following data:

$\mathrm{PD}=25$ Months

$\mathrm{SPI}=0.95$

Then from this data ED can be obtained as follows,

$\mathrm{ED}=(25 / 0.95)$

$=26.31 \approx 27$ Months

The time needed to complete all work on the EPCC Sugar Factory B Project are 27 Months, which shows that the completion time increased for 2 months from the initial planning.

\section{CONCLUSIONS}

The results obtained in this study indicate The Cost Performance Index of the Sugar Mill A EPCC Project, the Cooking Oil Plant Development Project and the Sugar Mill B EPCC Project with a progress of $20 \%$ is unstable by showing a $84 \%$ deviation. The stability of the CPI value of the 3 Projects occurred at a progress of $40 \%$ with a CPI value for the Sugar Mill A EPCC Project of 0.70, the Cooking Oil Plant Construction Project of 0.72 and the Sugar Mill EPCC Project of 0.79. The Schedule Performance Index of the Sugar Mill A EPCC Project, the Cooking Oil Plant Development Project and the Sugar Mill B EPCC Project with a progress of $20 \%$ is unstable by showing a $84 \%$ deviation. The stability of the CPI value of the 3 Projects occurred at $40 \%$ work progress with the CPI value for the Sugar Mill A EPCC Project at 0.77, the Cooking Oil Plant Construction Project at 0.95 and the Sugar Mill B EPCC Project at 0.83 . The stability of the CPI \& SPI at the $40 \%$ work progress shows that in its implementation, PT.XYZ projects have shown performance towards the completion of their work. Financial conditions and conditions of completion of work are at an appropriate ratio to be able to calculate EVM. Meanwhile, when compared to each project the value of the stability of the CPI \& SPI shows that cost control and work plans have been carried out properly because the variance was identified earlier and corrected in the appropriate period.

Earned Value Management parameters, namely SPI and CPI on the Sugar Mill A EPCC Project, Cooking Oil Plant Development Project and Sugar Mill B EPCC Project show both the work in the field (SPI) or budget planning (CPI), PT. XYZ is still showing not good enough performance. The Sugar Mill EPCC Project A shows that since the progress of work $23.37 \%$ the SPI value is below 1 and at the work progress $84 \%$ CPI value starts to be below 1 . The SPI value is below 1 indicating that the realization of completion of the work is slower than the original plan. In the Sugar Mill A EPCC project since the progress period of work $23.37 \%$ has been slower than planned in that period although cumulatively it is still better than planning. CPI values below 1 indicate that the budget needed for realization is more basic than the budget planned. The Cooking Oil Plant Development Project shows that since the progress of the work $48.33 \%$ the SPI value is below 1 and at the work progress $25.92 \%$ CPI value starts to be below 1 . The SPI value is below 1 indicating that the realization of completion of the work is slower than planned early. In the Cooking Oil Plant Development project since the progress period of work $48.33 \%$ has been slower compared to planning in that period although cumulatively it is still better than planning. CPI values below 1 indicate that the budget needed for realization is more basic than the budget planned. The Sugar Mill EPCC Project B shows that since the progress of work $58.1 \%$ the SPI value is below 1 and at the work progress $58.1 \%$ CPI 
value starts to be below 1 . The SPI value is below 1 indicating that the realization of completion of the work is slower than planned early. In the Sugar Mill EPCC project B since the progress period of work $58.1 \%$ has been slower than planned in that period although cumulatively still better than planning. CPI values below 1 indicate that the budget needed for realization is more basic than the budget planned. Analysis of Earned Value Management for EAC on the Sugar Mill A EPCC Project, Cooking Oil Plant Construction Project and Sugar Mill B EPCC Project shows that the cost required to complete the project is above the budget. The Sugar Mill EPCC Project A based on EVM will require $107 \%$ of the BAC value to complete the work, while the Cooking Oil Plant Development Project based on EVM will require $110 \%$ BAC for work completion and the Sugar Mill B EPCC Project based on EVM will require $106 \%$ BAC to complete the work. Referring to the EAC calculation and risk mitigation of the costs required, the Cooking Oil Plant Development Project has the greatest potential to be able to reduce operating results.
The actual rebaseline based only on the rest of the work does not provide budget certainty related to the acceleration of work that can be done and this has an impact on the value of the budget realization being greater than the planning of the new baseline budget which has an impact on reducing the company's business margins. Rebaseline by using the EVM method in addition to providing a prediction of the time needed to complete the EVM work, can also provide restrictions related to the use of the budget for acceleration in accordance with the EAC calculation above so that the budget rate can be managed.

\section{REFERENCES}

[1] Q. W. Fleming and J. M. Koppelman, Earned Value Project Management. Newtown Square: Project Management Institute, 2005.

[2] W. Abba, "Understanding Program Resource Management Through Earned Value Analysis.” PMI WDC Tool Time, 2006. 